\title{
Teachers' potential to promote students' deeper learning in whole-class teaching: An observation study in Norwegian classrooms
}

\author{
Randi M. Sølvik ${ }^{1}$ (D) Anne E. H. Glenna ${ }^{2}$
}

Accepted: 17 February 2021 / Published online: 17 March 2021

(C) The Author(s) 2021

\begin{abstract}
Teachers worldwide are challenged to adjust their teaching to meet students' needs for deeper learning. The lack of mutual understanding among researchers, policymakers and teachers tends to blur the discussion on how to enhance deeper learning through teaching, which further challenges teachers in making changes in their classroom practices. This qualitative observation study aims to explore how five skilled and experienced Norwegian teachers facilitate 10-16-year-old students' potential deeper learning in whole-class teaching. The teachers are videotaped four times during a school year, and observations show how teachers enhance or undermine students' active involvement, facilitate or hinder positive learning environments, support or impede deeper understanding, and stimulate or inhibit metacognitive reflection. The observations are discussed within a framework of the literature and research on how deeper learning is understood and promoted. The findings indicate how teachers' facilitation of a supportive learning environment is essential to actively involve students in the classroom interactions and dialogue needed to promote deeper content understanding and metacognitive reflection. We explore the potential for deeper learning within whole-class teaching and argue that such potential arises when teachers facilitate collective, reciprocal, supportive, cumulative and purposeful classroom interactions. Nevertheless, we acknowledge the importance of employing varied teaching practices to further address students' need for deeper learning. The study presents examples of whole-class teaching practices framed by theory and the earlier research on deeper learning, which may contribute to the concretization of policy changes in support of deeper learning in education.
\end{abstract}

Keywords Content understanding $\cdot$ Curricular change $\cdot$ Deeper learning $\cdot$ Learning environment · Metacognition · Observation study $\cdot$ Student involvement $\cdot$ Teaching practice $\cdot$ Wholeclass teaching

Randi M. Sølvik

randi.m.solvik@uis.no

Extended author information available on the last page of the article 


\section{Introduction}

For approximately two decades, there has been a worldwide focus on the skills and knowledge students need to succeed in work, life and citizenship in the twenty-first century (e.g., Rychen \& Salganik, 2003). A rapidly changing technology and society reduce the need for individual routine skills and challenge citizens to adapt, reflect, and solve problems in a creative, innovative, and collaborative manner. In the field of education, teachers are challenged to promote the development of such overlapping competencies in students to prepare them for future learning. This demand has been met by worldwide policies and renewed curricula focusing on students' deeper learning (e.g., Ministry of Education \& Research, 2017; Norwegian Directorate for Education \& Training, 2019) that have emphasized students' understanding of core ideas and connections within a domain as well as procedural competence in terms of how, when and why to apply knowledge to solve new problems and adapt to new situations (Bellanca, 2015; Pellegrino \& Hilton, 2012).

The distinction between surface learning and deep learning is not new within educational research (see for example Marton \& Säljö, 1976); however, the understanding of deep learning differs in terms of instructional principles, learning processes and outcomes. The lack of mutual understanding among researchers, policymakers and teachers tends to blur the discussion on how to deepen students' learning, which challenges schools' implementation of renewed curricula and teachers' changes in classroom practices. Thus, there is a risk that deep learning will merely serve as a slogan rather than becoming an integral part of teaching practice.

The present observation study aims to explore what five skilled and experienced Norwegian teachers do in their whole-class teaching to potentially promote or hinder 10- to 16-year-old students' deeper learning. Deeper learning is often presented as an overarching policy or aim for learning wherein long-term and inquiry-based, collaborative learning processes are emphasized (e.g., Pellegrino \& Hilton, 2012; Schwartz et al., 2005). Nevertheless, teacher-led whole-class teaching and plenary instruction are frequent activities in classrooms across the world (e.g., Klette, 2009; Kutnick et al., 2005). Relevant questions are therefore whether and how teachers can support and challenge students' deeper learning in the context of whole-class teaching. In this study, classroom observations of skilled teachers' whole-class teaching serve to explore the potential for deeper learning contextualized in a frequently used teaching practice. The quality of the interaction as well as the educational dialogue between teachers and students are seen as critical for the construction of deeper understanding and learning (e.g., Alexander, 2006; Darling-Hammond et al., 2020; Fullan \& Langworthy, 2014). Observations of teachers interacting with students in whole-class teaching, activating involvement and supporting dialogue to promote deeper understanding and metacognition contribute to illustrate teaching practices that potentially allow students to learn more deeply. Despite a large body of literature on deep learning as a construct and the educational factors that promote students' deeper 
learning (e.g., Fullan \& Langworthy, 2013; Pellegrino \& Hilton, 2012), there is a gap in the literature in terms of studies based on observations of plenary teaching exploring how teachers' practices potentially support or hinder students' deeper learning. By observing real-life classrooms and discussing how deeper learning is promoted and hindered within established classroom practices, the present study intends to concretize and add understanding with regard to how deeper learning can be facilitated.

To explore such teaching practices and their potential for deeper learning, it is necessary to define and problematize deeper learning as a construct. Classroom interactions are thus presented as a driving force in the exploration of teaching for deeper learning in whole-class practices, highlighting support of student involvement, deeper content understanding and metacognitive reflection. The literature review forms the basis for analyzing and discussing the findings from the observation study.

\section{Deeper learning}

The National Research Council's (NRC) review defines deeper learning as "the process through which an individual becomes capable of taking what was learned in one situation and applying it to new situations (i.e., transfer)" by developing cognitive, interpersonal and intrapersonal competencies (Pellegrino \& Hilton, 2012, p. 5). According to this definition, deeper learning occurs within three broad overlapping domains of human competencies: cognitive, intrapersonal, and interpersonal. Such competencies represent the essential attributes and goals of deeper learning. They prepare students to be creative, collaborative problem solvers who continue to learn throughout life (Barber et al., 2012; Fullan \& Langworthy, 2013, 2014). The student's capacity to reflect upon, adjust and lead his or her own learning is challenged and supported in deeper learning processes together with active involvement in dialogue and collaboration (e.g., Fullan \& Langworthy, 2014; Pellegrino \& Hilton, 2012). According to Smith and Colby (2007), deeper approaches to learning involve the intention to understand and impose meaning that is embedded in students' active engagement and involvement in the learning process. Gestalt psychologists (e.g., Katona, 1940) accordingly emphasize how meaningful learning processes, which include a deeper understanding of the structure of a problem and a solution method, lead to deeper learning.

Transfer is further highlighted as a central aspect of deeper learning (e.g., Bellanca, 2015; Fullan \& Langworthy, 2014; Pellegrino \& Hilton, 2012). Transfer has been a central topic in the research on learning and instruction for over 100 years; to date, the research has emphasized challenges to the understanding and measuring of transfer (e.g., Schwartz et al., 2005). Evidence supporting general transfer across subjects and disciplines is limited. More promising evidence is found to support the specific transfer of general principles (Pellegrino \& Hilton, 2012). However, an outstanding question is how the aim of transfer of competencies helps differentiate deeper learning from other types of learning as every learning process involves aims of transfer in one way or another. Bellanca (2015) describes how surface learning 
allows an individual to recall facts, concepts, or procedures while deeper learning processes challenge students to transfer facts, concepts and values to other lessons across subject-specific curricula and to apply their understanding to solve varied problems inside and outside school. Technology and digital access are highlighted as having potential for helping students apply knowledge and solutions to real-world problems outside of school (e.g., Fullan, 2013; Fullan \& Donnelly, 2013).

According to Schwartz and colleagues (2005), essential aspects of knowing and learning tend to be missed when understanding and assessing transfer due to people's ability to directly recall or apply what they have learned in a new setting. People's interpretations play a great role when learning both as a preparation for learning and as a basis for how to approach new problems. An alternative understanding of transfer is therefore to focus on how to prepare for future learning ('transferring in') rather than on how to apply skills and knowledge directly to new contexts ('transferring out') (Schwartz et al., 2005). How, then, may teachers facilitate deeper learning in whole-class settings?

\section{Teaching for deeper learning through classroom interactions}

In this study, classroom interactions are understood as a driving force when exploring teaching and learning in whole-class teaching practices. Human relationships are emphasized as essential in deeper learning processes, highlighting the coconstruction of learning (Fullan \& Langworthy, 2014). Teachers and students influence each other through reciprocal and circular interactions inside and outside the classroom. Recurring patterns of real-time interactions manifest relationships and underscore the strong role of teacher-student relationships in understanding teaching (Wubbels et al., 2015). The research indicates how teacher-student relationships and classroom interactions are more evident predictors of learning outcomes than structural factors such as class size and teacher-student ratio (Howes et al., 2008; Mashburn et al., 2008). According to meta-analyses of effective teacher-student relationships (e.g., Cornelius-White, 2007; Roorda et al., 2011), the quality of such relationships is associated with students' affective and cognitive outcomes. Warm, supportive teacher-student relationships are, for example, linked to better school performance and engagement, greater emotional regulation, social competence, and willingness to take risks in learning (Osher et al., 2020). Accordingly, contextual and structural factors affect students' learning and interactions through teachers' physical and social organization of the classroom and grouping of students (e.g., Blatchford \& Kutnick, 2014), emphasizing teachers' proactive role in driving and facilitating interactive learning processes (Fullan \& Langworthy, 2014).

The theoretical framework of Teaching Through Interactions (TTI) positions teacher-student interactions as central drivers for student engagement and learning and categorizes them into three major domains: emotional support, classroom organization and instructional support (Allen et al., 2013; Hamre et al., 2013; Pianta et al., 2012a). An observation manual, Classroom Assessment Scoring System-Secondary (CLASS-S), is designed to systematically code the quality of daily teacher-student interactions in secondary and lower-secondary classrooms across 
the three domains, and it includes dimensions with detailed teaching practices in each domain (see Hafen et al., 2015 for descriptions of the domain categories organizing the CLASS-S). According to TTI and CLASS-S, teachers facilitate students' learning through emotional support by creating a positive climate, being sensitive to students' needs and paying regard to adolescent perspectives; through classroom organization by proactive and effective management of behavior and instructional time to maximize students' learning and prevent a negative climate; and through instructional support by employing purposeful and varying instruction and methods, facilitating deeper content understanding, challenging analyses and inquiry, reassuring qualitative feedback and instructional dialogue (Allen et al., 2013; Hafen et al., 2015; Pianta et al., 2012a, 2012b). The research indicates how practices measured by the CLASS-S predict students' engagement and academic achievement in different countries (Allen et al., 2013; Virtanen et al., 2015; Westergård et al., 2019).

This study combines classroom interactions as driving forces for learning with the presented understanding of deeper learning. In further exploring teachers' potential for facilitating deeper learning in whole-class teaching, it emphasizes three areas: The first area of emphasis is the relevance of activating students' engagement and involvement. The second area of emphasis is the need to support students' deeper content understanding to set the stage and prepare for future learning. The third area of emphasis is the importance of enhancing students' ability to engage in metacognitive reflection and leveraging the social nature of learning.

\section{Facilitating active involvement}

Deeper approaches to learning integrate students' active engagement and involvement in the learning process (Darling-Hammond, 2008; DuFour \& Dufour, 2015; Smith \& Colby, 2007). Inquiry approaches to learning require, for example, active student involvement through questioning, considering of alternatives and applying knowledge (Darling-Hammond et al., 2020). Students' active engagement in collaboration with their peers has been recognized as important for individual cognitive development (Mercer \& Littleton, 2007); and jointly constructed knowledge is predicated on active, extended involvement (Mercer et al., 2019).

Students' interest and willingness to be involved in learning activities increase when teachers promote a positive and supportive learning environment (e.g., Darling-Hammond et al., 2020; Early et al., 2007; Hamre \& Pianta, 2005; Hoy \& Weinstein, 2006). Pellegrino and Hilton (2012, p. 7) state how "deep learning can be supported through teaching practices that create a positive learning community in which students gain content knowledge and also develop intrapersonal and interpersonal competences".

Classroom observations based on CLASS measure domains indicate how classroom interactions influence students' involvement and engagement in learning activities. Positive and supportive teacher-student interactions, understood through emotional support, enhance students' interest and willingness to participate in classroom activities, facilitate the development of their academic skills (Early et al., 2007; Hamre \& Pianta, 2005) and increase their motivation (Lerkkanen et al., 2012). Emotional support is also indirectly related to increasing students' experience of 
autonomy, competence, and affiliation (Ruzek et al., 2016). Emotional support thus contributes to positive processes within individual students and among groups of students and is important for students' learning and development.

The research indicates that a high level of instructional support relates to more positive and less negative teacher-student interactions, more engagement in the classroom (Downer et al., 2007) and higher academic outcomes among students (Mashburn et al., 2008; Pakarinen et al., 2011). A positive association has also been found between the quality of educational dialogue and students' academic performance in language arts and physics/chemistry (Muhonen et al., 2018). Furthermore, high-quality classroom organization relates to higher student engagement in learning activities (Rimm-Kaufman et al., 2009). Studies have also applied the CLASS-S in instructional coaching interventions to improve students' behavioral engagement (Allen et al., 2011).

\section{Supporting deeper content understanding}

Content knowledge plays an important role in shaping people's interpretations of new situations. What people bring to a situation affects what they gain from it. It is therefore important to activate and build upon students' prior knowledge to ensure a deeper understanding (Darling-Hammond, 2008; Schwartz et al., 2005). Teachers' instruction of students' content vocabulary through the identification of essential concepts, linking concepts to students' experiences and background knowledge, and acknowledging different meanings due to different contexts is therefore relevant (Phillips et al., 2008). Addressing and facilitating students' applicative knowing also support new learning and help students prepare for future learning (Schwartz et al., 2005). By activating domain-specific knowledge as well as an understanding of how to apply that knowledge, teachers facilitate a common platform for students to explore and construct new knowledge, progress their content understanding and develop reflective dialogues. Clearly defined learning goals combined with a model of how learning is expected to develop are recommended to establish a basis for effective feedback based on self-, peer- and teacher assessments (Fullan \& Langworthy, 2014; Pellegrino \& Hilton, 2012). Accordingly, effective teachers support interpretive knowledge and set the stage for interactive problem finding and problem solving by assembling platforms for subsequent learning (Fullan \& Langworthy, 2014; Schwartz et al., 2005). Similar elements of teaching are emphasized through the domain of instructional support in TTI and CLASS-S (e.g., Allen et al., 2013) as instructional learning format, content understanding, analyses and inquiry, quality of feedback and instructional dialogue.

In whole-class teaching practices, dialogue among teachers and students is essential for creating deeper understanding. According to Alexander (2006), five principles regulate the quality of educational dialogue. Dialogic teaching stimulates learning, reflection and understanding when it is (1) collective, (2) reciprocal, (3) supportive, (4) cumulative and (5) purposeful. The ways in which teachers build positive learning communities such that students are comfortable and involved influence how students express their thinking and respond others' ideas. Such approaches 
also lay the groundwork to further challenge and support students' deeper understanding across competencies and contexts.

Deeper learning goes beyond the mastery of existing content knowledge (Fullan \& Langworthy, 2014) and challenges us to strike a balance between efficient routines and more time-consuming innovations. To prepare students for future learning, Schwartz et al. (2005) bring attention to adaptive expertise to reduce the traditional gap between efficiency and innovation and to further develop the field of transfer. Adaptive expertise originates from Hatano and Inagaki (1986) as an alternative to routine expertise that mainly focuses on efficiency. Active interaction among people, tools and environments is essential within adaptive expertise to discover gaps and misalignments in one's knowledge and to gain access to new structures, interpretations, and forms of interaction.

\section{Supporting metacognitive reflection}

Teaching for deeper learning challenges teachers to activate students' awareness of the processes of learning. According to Fullan and Langworthy (2014, p.20), "this means interacting with students to make the students' thinking and questions about learning more visible." By enhancing content-independent strategies, such as critical thinking or metacognition, students are challenged to reflect upon what they know, what they need to know, and the processes required for solving and adapting to problems (Darling-Hammond, 2008). According to Pellegrino and Hilton (2012), these cognitive and intrapersonal competencies should be taught and assessed within specific disciplines and topics and not as stand-alone courses. For example, teachers of English or mathematics should question, monitor, and continuously provide feedback in ways that foster reflection, creativity, and reasoning. Accordingly, domainspecific instruction fosters creative thinking skills when they are explicitly taught and modeled (Tiruneh et al., 2018).

A challenge for developing adaptive expertise, however, is when thinking and problem-solving skills are taught as scripts or mechanical routines. Intensive and long-term processes are necessary to promote a learning environment that ensures adaptive expertise and blends efficiency and innovation. Students need opportunities to be innovative and interactive within a domain to reach beyond the immediately known (Schwartz et al., 2005). Rather than seeking and assessing correct, factual answers, teachers should challenge students' applicable knowing through inquirybased tasks and encourage them to explain their own cognitive processes and analyze and self-evaluate their problem solving (Darling-Hammond, 2008; DarlingHammond \& Conley, 2015).

Based on presented literature, teachers can facilitate the dynamics of interactive opportunities and support the potential for deeper learning in whole-class teaching by actively involving students, establishing and maintaining a supportive learning environment, promoting deeper understanding of content, and enhancing reflection upon students' learning processes and thinking. However, teaching quality varies across classrooms, and the quality of classroom interactions (e.g., Allen et al., 2013) as well as the quality of the educational dialogue (e.g., Alexander, 2006; Mercer \& Littleton, 2007) are critical for the construction of deeper understanding and 
learning in the classroom. It is therefore worthwhile to further explore skilled teachers' actions in the classroom and discuss how they potentially support or hinder students' deeper learning.

\section{Aims and research questions}

The present observation study aims to explore how skilled and experienced Norwegian teachers facilitate students' deeper learning in whole-class teaching. We specifically attempt to answer the following research question: What do teachers in this sample do in their whole-class teaching that potentially promotes or hinders 10- to 16-year-old students' deeper learning?

We seek to identify actions that enhance or undermine students' active involvement, facilitate or hinder a positive learning environment, support or impede deeper understanding, and stimulate or inhibit metacognitive reflection. Our findings will be discussed in relation to the literature presented in the introduction.

\section{Method}

\section{Overarching study}

The present study draws on data from an overarching mixed-method study on Classroom Interaction for Enhanced Student Learning (CIESL) that explored Norwegian classrooms for students from 10 to 16 years old. The data were collected through a mix of teacher and student surveys, interviews, and observations (e.g., Ertesvåg et al., 2020).

Within the overarching study, 81 of 450 teachers volunteered to be observed teaching a self-chosen subject. Video-recorded classroom observations of the teachers teaching the same subject and the same group of students four times during a school year were conducted. CLASS-S was used to score the video-recorded classroom observations. The results indicated that, in general, Norwegian teachers score from moderate to high on emotional support and classroom organization, rated on the 7-point scale measuring teacher-student interactions in CLASS-S: low (1-2), moderate (3-5) or high (6-7). However, more variation is observed, and there is greater potential for improvement with regard to instructional support in the classrooms (Virtanen et al., 2019; Westergård et al., 2019).

\section{Sampling of teachers and selection of video data}

As stated above, the CIESL study indicated that Norwegian teachers show most variation within instructional support. Accordingly, fewer teachers were scored moderate to high on instructional support (Westergård et al., 2019). In the present study, the observations of teachers' instructional support were therefore used to identify a purposeful and manageable group of potentially skilled and experienced teachers. Additionally, teachers' self-reporting consciousness of classroom interactions, based 
Table 1 Sample overview

\begin{tabular}{lllll}
\hline Sex & Subject & Grade & Students' age & $\begin{array}{l}\text { Video- } \\
\text { record- } \\
\text { ings }\end{array}$ \\
\hline Male & English & 10th & $15-16$ years & $3^{\text {a }}$ \\
Male & Mathematics & 8th & $13-14$ years & $3^{\text {b }}$ \\
Female & English & 10 th & $15-16$ years & 4 \\
Female & Mathematics & 5th & $10-11$ years & 4 \\
Female & Science & 7 th & $12-13$ years & 4 \\
\hline
\end{tabular}

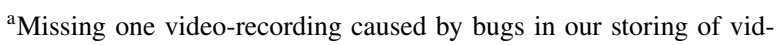
eos

${ }^{b}$ Missing one video-recording caused by bugs in our storing of videos

on teacher surveys, was used to make up a purposeful sample of five skilled teachers, all of whom had more than 6 years of teaching experience (Table 1).

Each of the sampled teachers was previously video-recorded in four isolated lessons during a school year: two times in the autumn and two times in the spring. The time points for the observations were adapted to the teachers' time-schedules and were planned ahead of the school year. We used one camera from the side or back of the classroom that followed the teachers' initiatives and actions, resulting in all students not always being present in the video-recording at the same time. Two microphones were used: one attached to the camera and one to the teacher. The camera captured the teachers' interactions with students and followed the teacher's movements in the classroom. The sampled data material included $18 \mathrm{~h}$ of videorecorded lessons.

\section{Ethics}

The teachers, students and parents received written and oral information about the project. They were informed that participation was voluntarily and that they could withdraw from the project at any time without consequences. A written consent form was obtained from the teachers. The students gave informed written consent together with their parents. Guidelines from the National Committee for Research Ethics in the Social Sciences and the Humanities (NESH, 2016) were followed, and the Norwegian Data Inspectorate at the Norwegian Centre for Research Data approved the project.

\section{Analysis}

\section{Process video data}

The sampled videos were condensed and transformed to words following an observational template with two foci: (1) descriptive field notes were written focusing on 
the structure, organization and flow of the lesson, the type and variation of lesson activities, and the classroom climate; (2) whole-class teaching episodes wherein teachers supported or challenged students' cognitive, intrapersonal or interpersonal competencies were identified and plotted to the video-recorded timeline.

These episodes were digitally transcribed and further imported and saved in QSR International's NVivo 11 software using anonymized identifiers corresponding both internally and externally with the overarching mixed-method study. The transcriptions covered teachers' and students' verbal expressions, framed by write-ups on the given context. Nonverbal expressions were documented as annotations when they added information to specific verbal expressions by supporting, challenging, or broadening the understanding of the transcribed verbal expressions.

The process of analysis was continuously interactive between the researchers and the data, between the data and the theory, and between the researchers. Videotaping improved the quality of the data collection because interactions could be reviewed multiple times (Klette \& Blikstad-Balas, 2018; Wubbels et al., 2015). Both researchers thoroughly examined each video. One of the researchers transcribed the video records into text. The other researcher read through the transcripts and noted where clarification was needed. The videos were thus reviewed, and the transcripts were elaborated. NVivo 11 was used to store, display, code, link and organize the data.

\section{Data coding}

We began with provisional coding based on researcher-generated codes derived from theory. These first-cycle codes were initially assigned to the data chunks to define meaningful units or topics within the data (Miles et al., 2014). Each video was coded separately one at a time by the two researchers. The coding was compared and discussed, resulting in modified and revised codes to establish clarity and to ensure consistent coding within and between the researchers. Interobserver reliability was not quantitatively measured; however, satisfactory levels of agreement were established after coding each video two times. In vivo codes, derived from expressions in the data material, were added as well as process codes connoting observable and conceptual action in the data. Fine-grained coding was used to explore the teaching practices in greater depth.

Second-cycle coding was used to cluster the first codes into a smaller number of categories (Miles et al., 2014). We used the coding tools "case" and "tree nodes" in NVivo 11 to cluster the codes. All data concerning the same teacher were grouped and defined as one "case". The "tree nodes" represented a hierarchical structure of codes containing "parent nodes" and "child nodes" (Richards, 2005). The main hierarchy of nodes was established after coding and recoding three lessons from three teachers based on the fit to the data material and the final focus of the analyses. Four parent nodes were established: Involvement, Learning environment, Content understanding, and Metacognitive reflection. Each of the four parent nodes included child nodes, establishing a tree structure for analysis (see Supplemented Appendix 1 for illustration). Figure 1 illustrates the tree structure of the parent node "Content understanding". 


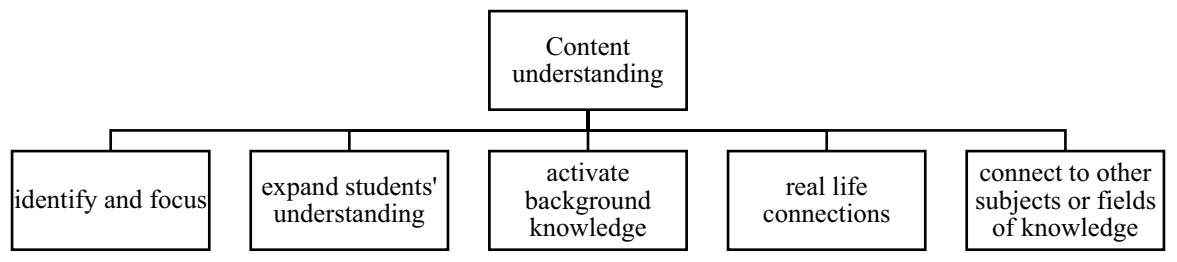

Fig. 1 Tree structure for Content Understanding

The parent node "Content understanding" included situations where the teachers identified and focused students' attention on learning goals, essential concepts, procedures or elements within the content presented or discussed in class. Further, it included how teachers expanded students' understanding by building on students' responses or providing additional information and clarification on the objects presented. The last three child nodes focused on situations where the teachers linked specific subject knowledge to other areas: activating students' prior and background knowledge; connecting to real-life by giving or asking for examples within students' everyday life and culture; and connecting to other subjects or fields of knowledge by emphasizing meaningful relationships among facts, skills, concepts or procedures.

Each of the four parent nodes was structured in a similar way to categorize essential aspects within the teachers' teaching practices. The two parent nodes (content understanding, metacognitive reflection) were theory-driven based on the research on deeper learning (e.g., Bellanca, 2015; Pellegrino \& Hilton, 2012) and TTI (e.g., Hamre et al., 2013). Involvement developed as a node in combination with theory and data when we discovered the importance of students' active involvement in our sampled classrooms and that it was essential for the teacher to follow up and challenge students' deeper understanding and reflection. Earlier research (e.g. DarlingHammond, 2008; DuFour \& Dufour, 2015; Mercer \& Littleton, 2007; Smith et al., 2009) also emphasizes this link between involvement and deeper learning. The node learning environment was data driven and, through the process of analysis, developed as an essential topic closely connected to students' involvement. The importance of a supportive learning environment for student's learning is also supported in the earlier research (e.g. Early et al., 2007; Hamre \& Pianta, 2005; Wubbels et al., 2015).

\section{Generate meaning}

The five teachers and their classrooms were grouped as separate cases in NVivo 11. Within-case analysis was used to describe the variables of teaching and to generate meaning from each classroom. Noting the patterns of the variables helped in establishing codes and hierarchies of codes. Patterns of processes were similarly noted and involved connections between pieces of data or codes. An example of an early noted pattern was the importance of a supportive learning environment for student involvement. 
Cross-case analysis was used to identify processes and outcomes across the five classrooms and teachers. Contrasts and comparisons were made between the teachers and their means of facilitating deeper learning, and the relationships between the variables were noted. One teacher and his classroom differed substantially from the others and can be described as an extreme case according to Miles et al. (2014).

To document and keep track of the process of analyses, analytical memos were attached to field notes, transcribed situations, and codes. These contained brief narratives documenting the researchers' reflections and thinking processes. They were typed and dated to capture thoughts that arose during the processes of data collection, data condensation, data display and conclusion making.

\section{Methodological integrity}

According to Levitt et al. (2018), methodological integrity can be evaluated through two composite processes: (1) fidelity to the subject matter and (2) utility in achieving research goals.

Fidelity to the subject matter concerns the process by which procedures are selected to develop and maintain allegiance to the studied phenomenon (Levitt et al., 2018). In this study, the data are collected to identify the variants of whole-class teaching practices relevant to expanding the understanding of how teachers support or hinder students' potential deeper learning. According to the data adequacy, the teachers were sampled based on their skills and consciousness concerning instructional support. Through a sample of skilled and experienced teachers, we increased the possibilities of observing relevant teaching practices. Accordingly, the data shed light upon variations within the observed teaching practices, which revealed interesting contrasts during the analysis.

Researchers' experience and background always influence a study. A relevant aspect of this study is how researchers with different backgrounds worked through the data to establish consensus. One of the researchers is a certified CLASS-S observer and has conducted and scored several videos. The other researcher is an experienced teacher educator and has no earlier experience with the CLASS-manual. The differences in our experience influenced and broadened our understanding of the data. However, similarities and contrasts in the data guided our analysis together with the presented theoretical framework. The use of videos strengthened this process as we were able to review the videos several times and to clarify the nonverbal and contextual elements documented in the text transcriptions. Although one data set was missing for two teachers, three hours of video data provided enough material to study how the teachers' actions supported or hindered students' potential deeper learning. The findings reflect the grounding of the process in the data and are presented as episodes based on the data.

The idea of utility in achieving research goals guided our selection of procedures to usefully answer the research questions and address our aim (Levitt et al., 2018). We sought to strengthen the utility of this study by describing our process of obtaining video data, data coding, the generation of meaning and the establishment of researcher consensus. Accordingly, the analyses identified findings that address the 
analytic goals, context information was provided for each illustrative episode, and contrasts and differences within the findings were noted and explained during the presentation. An audit trail was established through NVivo11 to document the process and analysis of the data from raw data to transcripts of episodes and field notes through the development of node structures.

\section{Findings}

To address the research question concerning what teachers do in whole-class teaching to potentially promote students' deeper learning, the findings are presented as descriptions of the teachers' actions. The four nodes-involvement, learning environment, content understanding, and metacognitive reflection-structure the following presentation of the findings.

\section{Enhancing student involvement}

A main finding concerning teachers' enhancement of students' involvement was how the teachers consistently varied their presentations of information through multiple modalities, instructional strategies, and materials employed. The teachers were well prepared and brought several materials that were ready for use. We observed that with well-organized, varied, interactive and adaptive presentations of material, the students appeared to be actively interested and engaged throughout the class.

One example illustrates how the female math teacher activated her 10- to 11-yearold students through multiple senses and skills.

\section{Episode 1.}

\section{Active involvement}

\section{Context:}

Classroom of female math teacher, teaching twenty-five 10- to 11-year-old students. The students are placed in rows facing the teacher, with two students at each table

The teacher has introduced two new topics, median and type number, through whole-class problem solving and dialogue. She asks her students to contribute to make a number line where the students each represent a number plate. All her students immediately raise their hands to join in the number line; many of them also stand up and wave their hand. The teacher picks seven students to come to the front of the classroom and gives each of them a piece of paper with a number.

\section{Episode:}

Teacher: Now, I want you to cooperate and find the median. What do you need to do?

The students look at each other's number plates and help each other sort themselves in ascending order. Teacher: Who is the median?

The student in the middle smiles, steps forward and raises his number.

(...)

Teacher: I have an extra challenge for you. (She turns to Peter, another student, and says) Peter, I have a number for you. Give a place in the row for Peter, please. Where is the median now?

The above example illustrates how the teacher facilitated the students' opportunities for interacting in the learning activity. The students showed willingness and 
eagerness to participate in the learning task by raising their hand and hardly being able to sit in their chairs. Eight of twenty-five students were challenged to cooperate verbally and physically by moving and changing places within the row of numbers. They were challenged to practice their new math skills and to solve the problem of finding the median. The teacher continued to challenge her students' understanding by gradually increasing the level of difficulty by including more numbers in the row. Additionally, she scaffolded the students' learning during the activity with questions and hints. Such verbal scaffolding was also observed in the other classrooms. The scaffolding approach was adapted to situations and students and enhanced the students' involvement in activities, tasks and reflection. More students were involved in similar tasks later in the lesson. In contrast, the male English teacher was not observed to promote similar involvement and engagement to that of the others.

\section{Episode 2.}

Passive involvement

Context:

Classroom of male English teacher, teaching nineteen 15- to 16-year-old students. The students are placed individually in rows facing the teacher

The situation is halfway through a 12-min teacher monologue at the beginning of the lesson. The learning target involves how to write an article in English

Episode:

Teacher: What do you need to write a good article? (He looks at his students and waits for some seconds before continuing). You cannot just start writing. You need to have good knowledge about the topic. You must inform yourself well, study background information, sources, so you have a solid background to be able to inform or convince the reader of your point of view in this. And then, of course, you need some knowledge about the text structure, language that you need. You need to know the right words for that topic. You need to know how to read an article. What is needed for that?

(the monologue continues)

This monologue illustrates how the English teacher failed to involve his students in exploring the topic of how to write an article. He asked relatively open questions, paused briefly, and looked at his students but received minimal responses and ended up answering the questions himself. In his English lessons, we observed a remarkably silent classroom containing distinctly less student involvement and engagement than in the other observed classrooms.

\section{Stimulating a positive learning environment}

The teachers' stimulation of a positive learning environment appeared to be an area with clear contrasts between the main group of teachers and the male English teacher. The main group, which contained four teachers, promoted a notably safe and comfortable climate of learning based on their interactions with their students. The learning climate was generally characterized by respectful interactions, frequent positive communication between teachers and students and matched enjoyment. These four teachers were aware of and sensitive to the students' academic and emotional needs in ways that enhanced the students' involvement and their search for support in the classroom. The positive climate was stable across each teacher's 
observed lesson and across the teachers. The teachers used different strategies to promote a supportive learning environment. Some shook hands and conversed with the students when they came into class, and they moved around in the classroom, checking in with students during class. They explicitly encouraged and supported the students' participation, ideas, and opinions in dialogue with the whole class or with groups of students. For example, the female science teacher addressed the value of the students' reflections during a whole-class dialogue.

Episode 3.

Valuing students' contributions

Context:

Classroom of female science teacher, teaching twenty-one 12- to 13-year-old students. The students are placed two by two in rows facing the teacher

The class is having a dialogue about the water cycle. The teacher asks questions to explore the water cycle, and the students are contributing with different answers. One student responds by explaining the transition between phases

Episode:

Teacher responds: You explained the phases, and you explained them very well. You did not explain the water cycle, but you explained the transition between the phases. They are important in the water cycle too because both evaporation and condensation are part of the water cycle. So, it is good that you repeated that for us

The science teacher explicitly acknowledged the value of her student's answer. Although transition between phases differed from the water cycle, she linked it to the original topic and emphasized how the contribution helped expand the class's understanding. She responded and emphasized the student's answer respectfully and valued the student's idea and contribution. This episode represented a typical example of how warm and supportive teacher-student interactions were observed in the main group of teachers.

In contrast, the male English teacher moved around in the classroom and checked in with his students; however, he was less sensitive to the students' academic and emotional needs and initiatives. He consistently failed to notice when students needed extra support or assistance. His students rarely shared their ideas with the teacher or responded to his questions voluntarily (Episode 2). To get the students talking, he moved around in the classroom and suddenly pointed at students to answer questions. The atmosphere seemed tense in contrast with the other classrooms.

\section{Facilitating deeper content understanding}

A main pattern across the lessons and teachers was how the teachers identified and focused learning targets and essential concepts and procedures. All the teachers began class by presenting the learning targets in a distinct manner. Their focus on content learning continued by addressing essential concepts, processes, or elements during the lesson, and they focused the dialogue and activities in accordance with 
the learning targets. Our observations showed that the students' initiatives and ideas were relevant for the objectives set for the lesson.

The following example illustrates how essential attributes of concepts and procedures were communicated early in the lesson and linked to the learning targets.

\section{Episode 4}

\section{Identifying concepts}

\section{Context:}

Classroom of female English teacher, teaching twenty 15- to 16-year-old students. The students are grouped at tables for 5-6 students facing each other.

The teacher begins the lesson by presenting a learning target written on the blackboard: "Develop listening skills and conversation skills" and identify central concepts. She asks questions, and several students respond and build on other students' answers

\section{Episode:}

The teacher focuses the chosen concepts by asking the following:

What does it mean to develop something?

You are going to develop listening skills. What does that mean?

How will we develop conversation skills?

The above example illustrates how the teachers typically focused on essential concepts to establish a common understanding in class. This teacher identified "develop", "listening skills" and "conversation skills" as central issues and received responses from some of the students in plenum.

The teachers used different techniques to expand and connect the students' content knowledge through instructions and oral explanations, the chosen modalities, or procedures, or both. Activating background knowledge and giving real-life examples were the approaches mostly observed in our data material. For example, after setting the learning target, the female English teacher continued by focusing on "culture" as an overarching concept found in the students' text.

\section{Episode 5}

\section{Connecting content}

\section{Context:}

Classroom of female English teacher, teaching twenty 15- to 16-year-old students. The students are grouped at tables for 5-6 students facing each other.

The students are going to read a text concerning two students from different cultures. Before doing so, the teacher asks her students to cooperate in groups, brainstorm for two minutes and make a mind map of what "culture" might be

\section{Episode:}

The teacher moves around in the class and checks in with some students who have not yet begun writing.

Teacher: What is a culture? Can culture be books, music...?

The students answer by giving some examples and start writing.

Teacher: Good. Culture can be many things. We can have one culture here. There might be another culture in the city. Is there a Norwegian culture, an indigenous culture? (...)

After two minutes, the teacher writes culture on the blackboard and asks the students to contribute by filling in a shared mind map. The students to whom she offered help are the first to raise their hands and speak. Most students participate actively and share their ideas of what culture might be 
The described episode is a typical illustration of how the teachers addressed a concept and connected its content to other areas. The teacher activated her students' background knowledge before reading a text. She helped her students expand and connect culture to other concepts, areas and subjects verbally through her questions, prompts and explanations and through her way of organizing the lecture using individual and whole-class approaches and instructional strategies such as brainstorming, learning partners and mind-mapping. Together, the teacher and students expanded the concept by generating multiple and varied examples and by connecting the content to the students' everyday life, addressing their interests. The teacher offered individualized support and acknowledged the students' different viewpoints on "culture".

\section{Supporting metacognitive reflection}

Tendencies of facilitating metacognition were observed in all classrooms, mainly through teacher-led activities. However, the analysis indicated substantial differences among the teachers in acknowledging students' metacognition. The math teachers were most frequently observed asking for students' examination, reflection and evaluation when facing tasks, problems or questions. The female math teacher most consistently focused on the processes of the students' answers. She praised the students' contributions, identified the students' problem-solving approaches and modeled thinking about thinking.

Focusing learning strategies were commonly used among the teachers, for example, by pinpointing and involving relevant techniques such as mind maps, keywords, summary, evaluation schemes, or ways of cooperating as learning partners or groups during the lesson. A more unusual example was when the female math teacher combined her teaching of a new mathematical topic with how the brain works when learning something new.

\section{Episode 6}

\section{Making stable traces in the brain}

\section{Context:}

Classroom of female math teacher, teaching twenty-five10- to 11-year-old students. The students are placed in rows facing the teacher, with two students at each table

The teacher has the students' attention and shows a picture of a brain on the smart board. A similar picture was shown the day before 


\section{Episode:}

Student A responds spontaneously: A brain.

Teacher: Yes, do you remember why? Do you remember I told you something about the brain yesterday? Student A: The brain grows

Teacher: Yes. Raise your hands if you remember I talked about the brain yesterday.

(Several students raise their hands)@Student B: You told us that the brain grows if we make mistakes.

Teacher: Yes, I did. Do you remember what we struggled with yesterday?@Student C: We made mis-

takes.

Teacher: Yes, what mistakes did we make?

Student B: The difficult numbers... When we should figure out how, where...

Teacher: Shall I put up the picture from yesterday?

Class: Yes.

Teacher: Do you remember this number?

Class: Yes.

Teacher: You were to write the number in expanded form. You had many good suggestions on how to do that, but there was only one right answer. I told you, however, that all the different suggestions were important because I see it a bit like this: Our thoughts crisscross our brain with electronic impulses to connect our knowledge (the teacher illustrates the impulses in the brain by drawing lines crisscrossing the brain on the smart board). Yesterday, the connections went crisscross, and the brain almost got overheated. So, we cannot just continue to make mistakes. Today, we have started to understand a bit more of the extended form, so we need to reestablish some stable connections in our brains. Take yesterday's task 26.3. What is the extended form?

]Student D: $20+6+0.3$

Teacher: OK. Now we will work in different ways repeatedly to make these connections in our brain (draws on the smart board). We need to make stable traces in the brain so that when you need to rewrite a number in extended form, you have trained [your brain] and can more quickly find the right track (points to the smart board)

The teacher combined subject teaching with both verbal and visual explanations in this example of what happens in the brain when we learn new things. Additionally, the episode illustrates how the teacher acknowledged the importance of taking risks and making mistakes to increase learning. A variant of enhancing metacognition was carried out by the same teacher.

\section{Episode 7}

\section{Investigating a problem}

Context:

Classroom of female math teacher, teaching twenty-five 10- to 11-year-old students. The teacher introduces the idea of a median as a new topic for the class. The students are organized in pairs. They sit in rows, and their attention is on the teacher

\section{Episode:}

Teacher: I need to find the median of these numbers. I want you to figure out what I am doing. You need to be detectives. My task is to find the median of these numbers. I do as follows: (the teacher writes 3-4-1 on the smart board. Then, she writes 1-3-4 and puts a circle around the number 3)

Teacher: Maybe some of you have figured out how I solved this task. Keep that idea in mind, and see if it fits when I solve the next task

(...)

After the teacher has solved three tasks on the smart board, she asks her students what she did. Together, the students, in dialogue with the teacher, identify the following procedure for identifying the median: Put the numbers in ascending order. Circle the number in the middle 
The students were challenged to identify and investigate a mathematical problem in the above example. The teacher solved a problem on the smart board and allowed the students to explain the procedures and construct a rule for solving similar tasks. Through an instructional dialogue in class, scaffolded by the teacher's questions, the students identified key procedures for identifying the median. Over half of the students actively contributed in the dialogue, and most of the students paid active attention to the dialogue. However, the length of the students' contributions was short, and the dialogue was led by the teacher. A third example of facilitating metacognition was when the teachers encouraged their students to explain answers through follow-up questions such as "How did you reach that answer?"

\section{Discussion}

The present study aimed to explore whole-class teaching practices for students' potential deeper learning by observing and discussing teaching in a purposeful sample of five skilled and experienced lower-secondary teachers in Norway. How the teachers supported and challenged their students' learning environment and involvement, and how they initiated, facilitated, or hindered their students' understanding and metacognitive reflection, are addressed below.

\section{Learning environment as fundament for student involvement}

A main finding illustrates how the teachers' ongoing facilitation and regulation of the learning environment influence the potential for student involvement in wholeclass settings. The observations revealed a notable discrepancy in our data concerning classroom climates. The environment for learning was mainly observed as supportive through the teachers' ways of acknowledging students' contributions and different understandings. Most of the teachers checked in with their students and were sensitive to their social and academic needs. The students replied through activity, initiatives, and responses in the classroom. These classroom interactions were characterized as respectful and sensitive, containing frequent positive utterances and matched enjoyment. However, the contrasting classroom, characterized by less sensitive and predictable interactions, revealed several missed opportunities for students' involvement. The teacher was repeatedly disrespectful. He humiliated his students by commenting derogatorily on their achievement levels or on their understanding of given tasks. He initiated dialogue through open questions but received minimal student responses. This classroom displayed a pattern in which sarcastic teacher comments caused the students to become quiet and inactive, reduced the students' involvement in learning tasks and activities, and hindered potential deeper learning processes.

Together, these contrasting observations illustrate a connection reviewed in theory among the learning environment, student involvement and students' potential to develop deeper understanding and reflect upon their own learning. According to Early et al. (2007), Hamre and Pianta (2005) and Hoy and Weinstein (2006), 
students' interest and willingness to be involved in learning activities increase when teachers promote a positive and supportive learning environment. Further, the research emphasizes students' active involvement as a prerequisite for deeper learning (Darling-Hammond, 2008; DuFour \& Dufour, 2015; Mercer \& Littleton, 2007). The findings of the current study indicated how an established safe and supportive learning climate enabled the teachers to pursue learning objects and allowed their students to take risks and share ideas in class. Analysis within and across cases emphasized how the teachers' facilitation of a positive climate and their sensitivity towards their students' needs in whole-class situations laid the groundwork for student involvement and instructional dialogue, acknowledging the importance of teacher-student interactions as central drivers of student learning (e.g., DarlingHammond et al., 2020; Howes, et al., 2008; Roorda et al., 2011).

\section{Supporting or hindering students' deeper understanding and metacognitive reflection}

An essential finding across the observed classrooms indicated both possibilities and hindrances in terms of how the teachers focused and supported students' deeper understanding and reflection in whole-class activities and dialogue. Alexander's (2006) principles of dialogic education give resonance to the ways in which the teachers interacted with their students in our data to develop a deeper understanding of the course content and to support the students' reflection on learning processes. According to Alexander (2006), dialogic teaching stimulates students' thinking, learning and understanding and extends interactions between students when it is (1) collective, (2) reciprocal, (3) supportive, (4) cumulative and (5) purposeful.

The findings indicated how the teachers planned and steered classroom discussions and activities purposefully according to specific learning objectives. They clearly communicated learning goals at the beginning of each lesson and continued to support their students' attention to the learning objectives through summaries, reorienting statements or logically sequenced presentations and activities throughout the lesson. These teacher-driven instructions framed the students' focus on content and facilitated deeper understanding through continuous exploration by presenting learning material multiple times through multiple modalities.

Central learning goals, concepts, procedures, and/or links were identified and collectively addressed through presentations or class discussions. According to Mercer et al. (2019), collective and jointly constructed knowledge and understanding is predicated on the active, extended involvement of students and teachers in verbal classroom interactions. The teachers in our data facilitated the involvement of students differently, which resulted in different levels of student involvement in different classrooms. In classrooms where the students were actively involved, several learning activities and dialogues were observed to be reciprocal between students and teachers. Reciprocity was, for example, supported by involving students in varying and adaptive activities, open questions, individualized support and clear behavioral expectations in the classroom. Nevertheless, the observations revealed huge potential to promote more student-centered activities and dialogue through a context 
of student interaction and a focus on students' inter- and intrapersonal competencies (e.g., Blatchford \& Kutnick, 2014; Blatchford et al., 2003). The teachers in this study were generally initiating and leading; they controlled the observed activities, and the students were mostly seated in rows facing the teacher.

The observed activities and discussions were cumulative in the sense of how the teachers linked concepts, facts and skills and expanded the collective understanding by placing the students' answers and viewpoints within a larger picture according to the learning targets. One observed way of facilitating cumulative teaching was how the teachers provided a collective ground for students' potential understanding and metacognition through their facilitation of content understanding. Gregory et al. (2013) highlight that a wealth of domain-specific knowledge allows students to gain expertise or fluency and thereby apply the flexible use of knowledge, which serves as a prerequisite for creative thinking. However, there is a challenge when teachers monitor how elements, processes and concepts link in different ways but fail to involve students in the cumulative process of critical thinking or problem solving. In such cases, the class misses out on the kinds of complementary perspectives that might emerge through dialogue between students and teachers.

We argue that when teachers manage to facilitate interactions and dialogue in the classroom that cover the principles of dialogic teaching (Alexander, 2006), the potential for students' deeper learning is similarly enhanced. Both interpersonal and cognitive competencies are challenged when teachers and students address content and learning tasks together (collective) and when they listen to each other and share viewpoints (reciprocal) freely without fear of embarrassment (supportive). Intrapersonal competencies may additionally be challenged within such interactions when participants build on their own and each other's ideas and link them to coherent lines of thinking and enquiry (cumulative). When teachers ask for reflection upon the learning process and expect adjustments according to specific learning goals (purposeful), metacognition and higher-order thinking can be addressed.

However, the potential for facilitating engaged classroom interactions enhancing students' deeper learning is not fully utilized within the frame of plenary work. The research on building creative thinking in the classroom (Gregory et al., 2013) and the research on dialogic processes in the classroom (Howe \& Abedin, 2013; Mercer \& Dawes, 2014; Mercer \& Howe, 2012; Mercer et al., 2019) both emphasize group work and coconstruction as important for future knowledge building. Whole-class teaching may cover the coconstruction of knowledge when it is based on dialogue, discussions or structured problem solving; however, it is a challenge to engage the active participation of all students in the classroom. According to Blatchford and Kutnick's research (2014), group work doubles pupils' levels of sustained, active engagement in learning and substantially increases the amount of high-level, thoughtful discussion between students.

Accordingly, the study's findings revealed an unused potential for addressing and verbally acknowledging content-independent strategies in the classroom. Learning strategies and processes were facilitated through interactive learning activities; however, effective ways of cocreating meaning and metacognition were seldom explicitly addressed and trained for. This aligns with extant classroom studies stating that pupils rarely receive training in the interpersonal skills needed for group work (e.g., 
Blatchford \& Kutnick, 2014). Further, tasks and questions in the five classrooms seldom required a high degree of problem-solving or higher-order thinking. However, some exceptions were observed. For example, the female math teacher challenged her students' in collective problem solving by involving them in a moveable number line (Episode 1) and addressed metacognitive processes in a learning brain (Episode 6). She allowed her students to participate physically, cognitively and collectively in learning tasks and efficiently addressed the different competencies involved. Within our data, it was the two math teachers who mainly challenged students' metacognition, for example, by asking their students to explain their own cognitive processes ("How did you get that answer?") or to investigate and explain the procedures of how the teacher solved a problem rather than asking for facts and correct answers (Episode 7). According to Dori et al. (2018), metacognition is central to teaching science, and there is ample research to support the role of metacognition in STEM education, which may explain why the facilitation of intrapersonal competence is easier to observe within mathematics than in other subjects. The research supports how content-independent strategies should be taught and assessed within specific disciplines and topics (Pellegrino \& Hilton, 2012; Schwartz et al., 2005).

\section{Concluding remarks}

A recent review of the science of learning literature (Darling-Hammond et al., 2020, pp.109-110) states the following:

"[H]umans learn more effectively when they are not anxious, fearful, or distracted by other pressing concerns; when the learning is connected to their prior knowledge and experience; when they are actively engaged; and when they have a reason to care about the content they are learning and can use it to deepen their understanding and to solve real questions or problems".

In line with the earlier research, our findings indicate how teachers' efforts in establishing supportive and positive learning environments increase students' involvement, which prepares the ground for promoting students' deeper understanding and facilitating reflection upon learning processes. Accordingly, this study reveals potential for the further development of teaching practices that challenge and support students to solve problems and be creative, collaborative and innovative. The observed teacher initiatives and classroom interactions in whole-class practices actualize essential elements supporting students' deeper learning. The current study thus contributes to concretize the call for deeper learning in education relevant to the implementation of future teaching.

\section{Strengths, limitations and implications}

The strengths of this study include our sampling processes and access to and observations of presumably skilled and experienced teachers who displayed teaching practices relevant to discuss within literature on deeper learning. The data sources 
and the chosen design allow for the exploration of purposeful episodes illustrating elements of how deeper learning can be supported and hindered through teachers' actions. Further, our use of video data provided a rich portrayal of classroom interactions and made it possible to review our data repeatedly and to establish consensus between the researchers. Whole-class teaching represents a dominant instructional practice and is accordingly relevant for studying educational policies and curricular aims. Nevertheless, we acknowledge how additional instructional practices are crucial to fully support students' deeper learning.

The limited time in each class and the lack of accounting for the teachers' intentions and the students' experiences represent relevant limitations of this study. The small sample size also makes it impossible to generalize the findings and draw conclusions. However, examples of teachers' initiatives and follow-ups in class illustrate elements of teaching relevant to the exploration of how teachers enhance or undermine students' active involvement, facilitate or hinder a positive learning environment, support or impede deeper content understanding, and address, question or inhibit students' metacognitive reflection in plenary teaching. Accordingly, the findings correspond to the earlier research acknowledging the potential for teachers to further stimulate students' active engagement, deeper understanding and metacognitive reflection through classroom interactions.

Based on the worldwide focus on future competencies for the twenty-first century, a clearer understanding of teaching practices that potentially foster deeper learning is relevant for policymakers to address the connection between curricula and teaching. Similarly, concretizing, categorizing, and reflecting upon how teaching practices potentially promote or hinder deeper learning are relevant for teachers. A strengthening focus for future research would be to explore in-depth the correlations between teaching and deeper learning. Accordingly, exploring schools' future implementation of curricular changes involving the facilitation of deeper learning is of interest for increasing teachers' and policymakers' mutual understanding of how to stimulate deeper learning processes in the classroom.

Supplementary Information The online version contains supplementary material available at (https:// doi.org/10.1007/s10833-021-09420-8).

Acknowledgement We are grateful to all teachers and students participating in the project. We also want to thank fellow researchers for their thoughtful comments and advise. This work was supported by the Research Council of Norway [grant number 238003].

Funding Open access funding provided by University Of Stavanger..

\section{Declaration}

Conflict of interest The author declare that they have no potential conflict of interests to declare.

Open Access This article is licensed under a Creative Commons Attribution 4.0 International License, which permits use, sharing, adaptation, distribution and reproduction in any medium or format, as long as you give appropriate credit to the original author(s) and the source, provide a link to the Creative Commons licence, and indicate if changes were made. The images or other third party material in this article are included in the article's Creative Commons licence, unless indicated otherwise in a credit line to the material. If material is not included in the article's Creative Commons licence and your intended use is 
not permitted by statutory regulation or exceeds the permitted use, you will need to obtain permission directly from the copyright holder. To view a copy of this licence, visit http://creativecommons.org/licen ses/by/4.0/.

\section{References}

Alexander, R. J. (2006). Towards dialogic teaching: Rethinking classroom talk. Cambridge: Dialogos.

Allen, J., Gregory, A., Mikami, A., Lun, J., Hamre, B., \& Pianta, R. (2013). Observations of Effective Teacher-Student Interactions in Secondary School Classrooms: Predicting student achievement with the classroom assessment scoring system-secondary. School Psychology Review, 42(1), 76-98. https ://doi.org/10.1080/02796015.2013.12087492

Allen, J. P., Pianta, R. C., Gregory, A., Mikami, A., \& Lun, J. (2011). An interaction-based approach to enhancing secondary school instruction and student achievement. Science, 19, 1034-1037. https:// doi.org/10.1126/science. 1207998

Barber, M., Rizvi, S., \& Donnelly, K. (2012). Oceans of innovation: the Atlantic, the Pacific, global leadership and the future of education. Penguin.

Bellanca, J. A. (2015). Introduction. Advancing a new Agenda. In J. A. Bellanca (Ed.), Deeper learning: beyond 21 st century skills. Bloomington: Solution Tree Press.

Blatchford, P., Kutnick, P., Baines, E., \& Galton, M. (2003). Toward a social pedagogy of classroom group work. International Journal of Educational Research, 39(1-2), 153-172. https://doi. org/10.1016/S0883-0355(03)00078-8

Blatchford, P., \& Kutnick, P. (2014). Effective group work in primary school classrooms. The SPRinG Approach. Professional learning and development in schools and higher education (Vol. 8). Dordrecht: Springer.

Cornelius-White, J. (2007). Learner-centered teacher-student relationships are effective: a meta-analysis. Review of educational research, 77(1), 113-143. https://doi.org/10.3102/003465430298563

Darling-Hammond, L. (2008). Coclusion: Creating schools that develop understanding. In L. DarlingHammond (Ed.), Powerful learning. What we know about teaching for understanding (1st ed.). Jossey-Bass: San Fransisco.

Darling-Hammond, L., \& Conley, D. T. (2015). Assessment systems for deeper learning. In J. A. Bellanca (Ed.), Deeper learning. Beyond 21st century skills (pp. 235-271). Bloomington: Solution Tree Press.

Darling-Hammond, L., Flook, L., Cook-Harvey, C., Barron, B., \& Osher, D. (2020). Implications for educational practice of the science of learning and development. Applied Developmental Science, 24(2), 97-140. https://doi.org/10.1080/10888691.2018.1537791

Dori, Y. J., Mevarech, Z. R., \& Baker, D. R. (2018). Cognition, Metacognition, and Culture in STEM Education. Springer. https://doi.org/10.1007/978-3-319-66659-4

Downer, J. T., Rimm-Kaufman, S. E., \& Pianta, R. C. (2007). How do classroom conditions and children's risk for school problems contribute to children's behavioral engagement in learning? School Psychology Review, 36(3), 413-432. https://doi.org/10.1080/02796015.2007.12087938

DuFour, R., \& Dufour, R. (2015). Deeper Learning for Students Requires Deeper Learning for Educators. In J. A. Bellanca (Ed.), Deeper learning Beyond 21st century skills. Bloomington: Solution Tree Press.

Early, D. M., Maxwell, K. L., Burchinal, M., Alva, S., Bender, R. H., Bryant, D., \& Griffin, J. A. (2007). Teachers' education, classroom quality, and young children's academic skills: Results from seven studies of preschool programs. Child development, 78(2), 558-580. https://doi.org/10.111 1/j.1467-8624.2007.01014.x

Ertesvåg, S. K., Sammons, P., \& Blossing, U. (2020). Integrating data in a complex mixed-methods classroom interaction study. British Educational Research Journal. https://doi.org/10.1002/BERJ.3678

Fullan, M. (2013). Stratosphere: integrating technology, pedagogy, and change knowledge. Pearson.

Fullan, M., \& Donnelly, K. (2013). Alive in the swamp: Assessing digital innovations. London: Nesta; Oakland, CA.: New schools venture funds.

Fullan, M., \& Langworthy, M. (2013). Towards a New End: New Pedagogies for Deep Learning. Retrieved December 15, 2020, from http://www.newpedagogies.org/. 
Fullan, M., \& Langworthy, M. (2014). A rich seam: how new pedagogies find deep learning. Pearson.

Gregory, E., Hardiman, M., Yarmolinskaya, J., Rinne, L., \& Limb, C. (2013). Building creative thinking in the classroom: From research to practice. International Journal of Educational Research, 62, 43-50. https://doi.org/10.1016/j.ijer.2013.06.003

Hafen, C. A., Hamre, B. K., Allen, J. P., Bell, C. A., Gitomer, D. H., \& Pianta, R. C. (2015). Teaching through interactions in secondary school classrooms: Revisiting the factor structure and practical application of the Classroom Assessment Scoring System-Secondary. The Journal of Early Adolescence, 35(5-6), 651-680. https://doi.org/10.1177/0272431614537117

Hamre, B. K., \& Pianta, R. C. (2005). Can instructional and emotional support in the first-grade classroom make a difference for children at risk of school failure? Child development, 76(5), 949-967. https://doi.org/10.1111/j.1467-8624.2005.00889.x

Hamre, B. K., Pianta, R. C., Downer, J. T., DeCoster, J., Mashburn, A. J., Jones, S. M., \& Hamagami, A. (2013). Teaching through Interactions: Testing a Developmental Framework of Teacher Effectiveness in over 4,000 Classrooms. The Elementary School Journal, 113(4), 461-487. https://doi. org/10.1086/669616

Hatano, G., \& Inagaki, K. (1986). Two courses of expertise. In H. A. H. Stevenson, H. Azuma, \& K. Hakuta (Eds.), Child development and education in Japan (pp. 262-272). New York: Freeman.

Howe, C., \& Abedin, M. (2013). Classroom dialogue: A systematic review across four decades of research. Cambridge journal of education, 43(3), 325-356. https://doi.org/10.1080/0305764X.2013.786024

Howes, C., Burchinal, M., Pianta, R., Bryant, D., Early, D., Clifford, R., \& Barbarin, O. (2008). Ready to learn? Children's pre-academic achievement in pre-kindergarten programs. Early Childhood Research Quarterly, 23(1), 27-50. https://doi.org/10.1016/j.ecresq.2007.05.002

Hoy, A. W., \& Weinstein, C. S. (2006). Student and Teacher Perspectives on Classroom Management. In C. M. Evertson \& C. S. Weinstein (Eds.), Handbook of Classroom Management. Research, Practice, and Contemporary Issues (pp. 181-219). Mahwah, NJ: Lawrence Erlbaum Associates.

Katona, G. (1940). Organizing and memorizing: studies in the psychology of learning and teaching. Columbia University Press.

Klette, K. (2009). Challenges in strategies for complexity reduction in video studies. Experiences from the PISA+ study: A video study of teaching and learning in Norway. In T. Janík \& T. Seidel (Eds.), The Power of video studies in investigating teaching and learning in the classroom (pp. 61-82). Münster: Waxmann.

Klette, K., \& Blikstad-Balas, M. (2018). Observation manuals as lenses to classroom teaching: Pitfalls and possibilities. European Educational Research Journal, 17(1), 129-146. https://doi.org/10.1177/14749 04117703228

Kutnick, P., Blatchford, P., \& Baines, E. (2005). Grouping of pupils in secondary school classrooms: Possible links between pedagogy and learning. Social psychology of education, 8(4), 349-374. https://doi. org/10.1007/s11218-005-1212-1

Lerkkanen, M.-K., Kiuru, N., Pakarinen, E., Viljaranta, J., Poikkeus, A.-M., Rasku-Puttonen, H., \& Nurmi, J.-E. (2012). The role of teaching practices in the development of children's interest in reading and mathematics in kindergarten. Contemporary Educational Psychology, 37(4), 266-279. https://doi. org/10.1016/j.cedpsych.2011.03.004

Levitt, H. M., Bamberg, M., Creswell, J. W., Frost, D. M., Josselson, R., \& Suárez-Orozco, C. (2018). Journal article reporting standards for qualitative primary, qualitative meta-analytic, and mixed methods research in psychology: the APA publications and communications board task force report. American Psycologist, 73(1), 26-46. https://doi.org/10.1037/amp0000151

Marton, F., \& Säljö, R. (1976). On qualitative differences in learning: I-outcome and process*. British Journal of Educational Psychology, 46(1), 4-11. https://doi.org/10.1111/j.2044-8279.1976.tb02980.x

Mashburn, A. J., Pianta, R. C., Hamre, B. K., Downer, J. T., Barbarin, O. A., Bryant, D., \& Howes, C. (2008). Measures of classroom quality in prekindergarten and children's development of academic, language, and social skills. Child development, 79(3), 732-749. https://doi.org/10.1111/j.1467-8624.2008.01154 . $\mathrm{X}$

Mercer, N., \& Dawes, L. (2014). The study of talk between teachers and students, from the 1970s until the 2010s. Oxford Review of Education, 40(4), 430-445. https://doi.org/10.1080/03054985.2014.934087

Mercer, N., Hennessy, S., \& Warwick, P. (2019). Dialogue, thinking together and digital technology in the classroom: Some educational implications of a continuing line of inquiry. International Journal of Educational Research, 97, 187-199. https://doi.org/10.1016/j.ijer.2017.08.007 
Mercer, N., \& Howe, C. (2012). Explaining the dialogic processes of teaching and learning: The value and potential of sociocultural theory. Learning, Culture and Social Interaction, 1(1), 12-21. https://doi. org/10.1016/j.lcsi.2012.03.001

Mercer, N., \& Littleton, K. (2007). Dialogue and the development of children's thinking: A sociocultural approach. Routledge.

Miles, M. B., Huberman, A. M., \& Saldana, J. (2014). Qualitative data analysis. A methods sourcebook (3rd ed.). Sage.

Ministry of Education and Research. (2017). Overordnet del - verdier og prinsipper for grunnopplæringen. [Core curriculum - values and principles for primary and secondary education]. https://www.udir.no/ lk20/overordnet-del/?lang=eng

Muhonen, H., Pakarinen, E., Poikkeus, A. M., Lerkkanen, M. K., \& Rasku-Puttonen, H. (2018). Quality of educational dialogue and association with students' academic performance. Learning and Instruction, 55, 67-79. https://doi.org/10.1016/j.learninstruc.2017.09.007

NESH. (2016). Guidelines for research ethics in the social sciences, humanities, law and theology (4th ed.). Oslo: The Norwegian National Research Ethics Committees.

Norwegian Directorate for Education and Training. (2019). Læreplaner i grunnskolen [Curriculum for primary and secondary education]. https://www.udir.no/laring-og-trivsel/lareplanverket/Nye-lareplaner -i-grunnskolen-og-gjennomgaende-fag-vgo/

Osher, D., Cantor, P., Berg, J., Steyer, L., \& Rose, T. (2020). Drivers of human development: How relationships and context shape learning and development. Applied Developmental Science, 24(1), 6-36. https ://doi.org/10.1080/10888691.2017.1398650

Pakarinen, E., Kiuru, N., Lerkkanen, M.-K., Poikkeus, A.-M., Ahonen, T., \& Nurmi, J.-E. (2011). Instructional support predicts children's task avoidance in kindergarten. Early Childhood Research Quarterly, 26(3), 376-386. https://doi.org/10.1016/j.ecresq.2010.11.003

Pellegrino, J. W., \& Hilton, M. L. (2012). Education for life and work: developing transferable knowledge and skills in the 21st century. The National Academies Press.

Phillips, D. C. K., Foote, C. J., \& Harper, L. J. (2008). STRATEGIES FOR EFFECTIVE VOCABULARY INSTRUCTION. Reading Improvement, 45(2), 62-68.

Pianta, R. C., Hamre, B. K., \& Allen, J. P. (2012a). Teacher-Student Relationships and Engagement: Conceptualizing, Measuring, and Improving the Capacity of Classroom Interactions. In S. Christenson, A. Reschly, \& C. Wylie (Eds.), Handbook of Research on Student Engagement (pp. 365-386). Boston, MA: Springer.

Pianta, R. C., Hamre, B. K., \& Mintz, S. L. (2012b). Classroom assessment scoring system: secondary class. Teachstone.

Richards, L. (2005). Handling qualitative data. A practical guide. Sage Publications.

Rimm-Kaufman, S. E., Curby, T. W., Grimm, K. J., Nathanson, L., \& Brock, L. L. (2009). The contribution of children's self-regulation and classroom quality to children's adaptive behaviors in the kindergarten classroom. Developmental psychology, 45(4), 958-972. https://doi.org/10.1037/a0015861

Roorda, D. L., Koomen, H. M. Y., Spilt, J. L., \& Oort, F. J. (2011). The influence of affective teacher-student relationships on students' school engagement and achievement: A meta-analytic approach. Review of educational research, 81(4), 493-529. https://doi.org/10.3102/0034654311421793

Ruzek, E. A., Hafen, C. A., Allen, J. P., Gregory, A., Mikami, A. Y., \& Pianta, R. C. (2016). How teacher emotional support motivates students: The mediating roles of perceived peer relatedness, autonomy support, and competence. Learning and instruction, 42, 95-103. https://doi.org/10.1016/j.learninstr uc. 2016.01.004

Rychen, D. S., \& Salganik, L. H. (Eds.). (2003). Key competencies for a successful life and a well-functioning society. Hogrefe Publishing.

Schwartz, D. L., Bransford, J. D., \& Sears, D. (2005). Efficency and innovation in transfer. In J. Mestre (Ed.), Transfer of learning: Research and perspectives. Greenwich, CT: Information Age Publishing.

Smith, J. A., Larkin, M., \& Flowers, P. (2009). Interpretative phenomenological analysis: theory, method and research. SAGE.

Smith, T. W., \& Colby, S. A. (2007). Teaching for deep learning. The clearing house: A journal of educational strategies, issues and ideas, 80(5), 205-210. https://doi.org/10.3200/TCHS.80.5.205-210

Tiruneh, D. T., Gu, X., De Cock, M., \& Elen, J. (2018). Systematic design of domain-specific instruction on near and far transfer of critical thinking skills. International Journal of Educational Research, 87, 1-11. https://doi.org/10.1016/j.ijer.2017.10.005 
Virtanen, T. E., Lerkkanen, M. K., Poikkeus, A. M., \& Kuorelahti, M. (2015). The relationship between classroom quality and students' engagement in secondary school. Educational Psychology, 35(8), 963983. https://doi.org/10.1080/01443410.2013.822961

Virtanen, T., Vaaland, G. S., \& Ertesvåg, S. K. (2019). Associations between patterns of observed classroom interactions and teacher well-being. Teaching and Teacher Education, 77, 240-252. https://doi. org/10.1016/j.tate.2018.10.013

Westergård, E., Ertesvåg, S. K., \& Rafaelsen, F. (2019). A preliminary validity of the classroom assessment scoring system in norwegian lower-secondary schools. Scandinavian Journal of Educational Research, 63(4), 566-584. https://doi.org/10.1080/00313831.2017.1415964

Wubbels, T., Brekelmans, M., Den Brook, P., Wijsman, L., Mainhard, T., \& van Tartwijk, J. (2015). Teacherstudent relationships and classroom management. In E. T. Emmer \& E. J. Sabornie (Eds.), Handbook of Classroom Management (2nd ed., pp. 363-386). New York: Routledge.

Publisher's Note Springer Nature remains neutral with regard to jurisdictional claims in published maps and institutional affiliations.

\section{Authors and Affiliations}

\section{Randi M. Sølvik ${ }^{1}$ (D) Anne E. H. Glenna ${ }^{2}$}

1 Norwegian Centre for Learning Environment and Behavioural Research in Education, University of Stavanger, Kjølnes Ring 30, 3918 Porsgrunn, Norway

2 University of South-Eastern Norway, Notodden, Norway 